\title{
Varieties of Epistemic Freedom
}

\author{
Alison Fernandes
}

\begin{abstract}
When we deliberate about what to do, we appear free to decide on different options. Three accounts use ordinary beliefs to explain this apparent freedom, explicating different notions of 'epistemic freedom'. Under these accounts, the evidence an agent has while deliberating does not determine what decision she makes. This 'epistemic gap' between her evidence and decision explains why her decision appears free. These accounts might appear similar. But there is an important difference. Two accounts appeal to an agent's ability to justifiably form beliefs unconstrained by evidence. These identify decisions as beliefs - either beliefs about acts (Velleman) or decisions (Joyce and Ismael). These accounts face serious problems. Firstly, agents turn out to have epistemic freedom over beliefs formed in response to evidence. Secondly, these accounts rely on a flawed notion of justification. Underlying these troubles, it turns out they presuppose an unexplained apparent ability to form beliefs 'at will'. A third account of epistemic freedom uses ignorance conditions instead: we appear free to decide partly because we're ignorant of what we'll decide (Levi and Kapitan). Ignorance accounts avoid the above problems. Whether they are ultimately successful, the distinction between these varieties of epistemic freedom is crucial.
\end{abstract}

This is a preprint of an article whose final and definitive form is published in the Australasian Journal of Philosophy [2016]availble at https://www.tandfonline.com/doi/full/10.1080/00048402.2015.1116015 


\section{Introduction}

When Tamsin deliberates about whether she will head to bed or stay up reading, these options appear to her as possibilities she is free to decide on. How might we account for this apparent freedom? A number of accounts appeal to ordinary beliefs about the world, bodily motions and mental states (rather than beliefs in metaphysical freedom or normative beliefs). The central idea is that an agent's beliefs while deliberating do not compel her to decide any particular way. So there is a kind of 'epistemic gap' between her evidence and her decision. This gives her 'epistemic freedom' regarding her decisions (a term from Velleman 1989a). Velleman, Joyce, Ismael, Levi and Kapitan all offer accounts of epistemic freedom. Velleman, Ismael and Kapitan also use epistemic freedom to account for apparent freedom. It is because our decisions are uncompelled by evidence that we appear free while deliberating.

Accounts of epistemic freedom can look similar. And they're sometimes used interchangeably when giving accounts of causation that appeal to deliberation (Price 2012). But these accounts are importantly different. Two appeal to an agent's ability to justifiably form beliefs unconstrained by evidence, and identify decisions as beliefs. Velleman $(1985,1989 a, 1989 b)$ takes decisions to be beliefs about actions; Joyce (2002) and Ismael $(2007,2012)$ take decisions to be beliefs about decisions. They claim we can justifiably form these beliefs, even if we lack evidence for them or have evidence against them. This is the source of our epistemic freedom, which in turn explains apparent freedom. But these accounts face serious problems. Firstly, agents turn out to have epistemic freedom even over ordinary beliefs formed in response to evidence. Secondly, these accounts rely on a flawed notion of justification. Agents aren’t justified in forming beliefs unconstrained by evidence. At 
most the relevant beliefs are justified once formed. I argue that these accounts in fact rely on an unexplained apparent ability to form beliefs 'at will'. But once we introduce such a primitive ability, the appeal to epistemic freedom becomes redundant — there are simpler routes to explaining apparent freedom.

A third account of epistemic freedom based in ignorance conditions does better. Agents appear free in deliberation partly because their evidence leaves open how they will decide. The ignorance account I consider appeals to Levi's epistemic conditions on deliberation $(1986,1997,2000)$ and is similar to Kapitan's account of 'doxastic freedom' $(1986,1989)$. I won't defend this account in full-my aim is to show that these three types of account are importantly distinct, and that unconstraint accounts face significant problems. Ignorance accounts are a promising alternative.

Why be concerned with accounts of epistemic freedom? My main interest is whether they can explain our apparent freedom in deliberation. If we're not free, these accounts can be used to explain why we mistakenly appear so (Velleman 1989b). If we are free, these accounts can offer compatibilist accounts of this freedom (Kapitan 1986, 1989). In either case, we've learnt something important. The distinct advantage of epistemic accounts is that they only appeal to ordinary beliefs to explain apparent freedom. They appeal to beliefs that are less mysterious than the appearance of freedom we are trying to explain.

There are other uses for epistemic freedom. It might explain general features of the phenomenology of agency, such as why the future appears open (Ismael 2012). Some accounts also imply conditions on what options are available to an agent in 
deliberation, and so are relevant to decision theory, particularly debates between evidential and causal decision theorists (Levi 1986, 1997, 2000; Joyce 2002, 2007). And these accounts might explain how we have practical knowledge of our actions (Velleman 1985, 1989a). Finally, accounts of epistemic freedom are also relevant for accounts of causation. Price characterises causation in terms of the evidential relations that appear from an agent's perspective $(1992,2012)$. Others justify particular accounts of causation by appealing to epistemic features of deliberation (Mellor 1988; Hitchcock 1996 pp. 519-22; Pearl 2000 pp. 107-12; Ismael 2007). For these appeals to work, we must correctly identify the evidence of deliberating agents.

Before I begin, a few preliminaries. These accounts of epistemic freedom were developed in different areas of philosophy. To compare them, I have been flexible regarding what precisely they explain. Accounts might explain a phenomenal feeling of freedom (Velleman) or openness (Ismael, Velleman) or a belief in freedom or openness (Kapitan). These are all ways of capturing something about our experience as deliberators when we consider options before us and take these to be open alternatives we might decide on. I don't presume this appearance of freedom is veridical. I also consider accounts of epistemic freedom that weren't developed to explain apparent freedom at all. Joyce and Levi use epistemic freedom primarily to account for what options are rationally available to an agent. But there should be a close connection between what options are rationally available, and what options we appear free to choose.

I follow the majority of accounts in discussing decision rather than intention. While Velleman uses 'intention', he characterises this as what we're 'decided' on, and 
distinguishes it from the goal with which we act (1989a, pp. 112-3). We can also distinguish between the act of deciding and the product of that act. I'll discuss boththe former primarily as forming a decision, the latter as decision. I assume decisions both conclude deliberation and imply beliefs about what one will do. This is common ground between the accounts - for further discussion, see Hampshire and Hart (1958), Pears (1968) and Grice (1971). For simplicity, I take agents to decide on actions, rather than propositions - they decide on what they will do. But none of my arguments depend on how options are characterised. All these assumptions may need to be revisited in pursuing specific projects. They are made to compare these diverse accounts on the specific question of epistemic freedom.

The paper proceeds as follows. In section 2 I summarise the three accounts of epistemic freedom. In section 3 I argue that despite their similarities, they are importantly different. In section 4 I present two problems for unconstraint accounts, which ignorance accounts avoid. Finally, in section 5, I diagnose what I take to be the underlying trouble - unconstraint accounts rely on a primitive apparent ability to believe at will. So if we're to appeal to beliefs to explain apparent freedom, ignorance accounts offer a more compelling alternative.

\section{Three Accounts of Epistemic Freedom}

\subsection{Decisions as Unconstrained Self-fulfilling Beliefs}

How might we account for an agent's apparent freedom in deliberation? Velleman claims an agent appears free because she is justified in forming a variety of selffulfilling beliefs about what she will do (1985, 1989a, 1989b). These are beliefs that cause the very states of affairs they represent, and, furthermore, constitute her 
decisions. For example, say Tamsin is deliberating about whether to go to bed or stay up reading. She is somewhat motivated to go to bed, and somewhat motivated to stay up. Velleman claims that, as an agent, Tamsin has a standing desire, perhaps a subpersonal one, to know what she's doing as she begins to do it. This motivates her to act as she expects. So if she believes she'll stay up, this additional motivation may be enough to tip the balance and cause her to stay up. And similarly if she believes she'll go to bed. If so, her beliefs are self-fulfilling.

If these beliefs are to count as decisions, Velleman also requires the agent know the beliefs are self-fulfilling. Decisions are self-fulfilling beliefs that 'represent themselves' as such (1989a, p. 98). If her belief is a decision, then once Tamsin has formed the belief, she has evidence of its truth-evidence that comes from having the belief itself combined with the belief that it is self-fulfilling. And so, Velleman argues, her beliefs are still responsible for being true, still governed by appropriate evidential norms, and so still count as beliefs (1989a, pp. 56-64, 128-9). Velleman also argues that Tamsin is justified in forming a variety of self-fulfilling beliefs, safe in the knowledge that what she believes will turn out to be true. So she's unconstrained by her evidence of what she'll decide or do-she has 'epistemic freedom' (1989a, ch. 5; 1989b; 2000, pp. 22-6, ch. 2). This is 'the freedom to affirm any one of several incompatible propositions without risk of being wrong' (1989b, p. 73). She has this epistemic freedom whenever she knows, for at least two beliefs that are incompatible, that either would be true if formed. Because she can form beliefs as she likes in these cases, and still be justified, no wonder she appears free to decide in different ways: 'we mistake the license to affirm any one of various things about what 
we'll do for the [metaphysical] possibility that we might do any one of those things' (1989b, p. 74). ${ }^{1}$

Evidential unconstraint plays a central role in Velleman's explanation. What makes an agent 'feel free' is her 'freedom from the evidence' (1989b, p. 77). Tamsin is not constrained by evidence about what she will decide or do. Even if she has evidence that she won't go to bed, or won't form the belief, she can still know that the belief would be self-fulfilling, were she to form it. This gives her epistemic freedom concerning it. She is 'licensed' to form this belief, even if the totality of her evidence is conclusive and guarantees the belief is false (1989a pp. 149-153, 166; 1989b, pp. 78-80). So freedom is not a matter of ignorance. Adapting an example from Anscombe, Velleman argues that a doctor is licensed to make various predictions of where a nurse will take the patient, even when he knows where the patient will go:

The evidence...contains one component that licenses the doctor to contradict what all of the evidence, taken together, conclusively proves. This component of evidence shows that the doctor would be correct in predicting whatever he likes, within reason, irrespective of what the totality of evidence demonstrates is bound to occur...The central evidence shows the doctor that even if the totality of evidence guarantees one outcome, he would still be correct in predicting others. It shows, in short, that he is epistemically free. (1989b, p. 79)

\footnotetext{
${ }^{1}$ Related accounts include Harman (1976) and Joyce (2007, pp. 556-61). Harman takes decisions to merely 'involve' beliefs, and doesn't use beliefs to explain apparent freedom. Joyce generalises Velleman's account to include common cause structures, but doesn't suggest how beliefs function like decisions, or why we might appear free with respect to them.
} 
There are some ways in which evidence limits epistemic freedom (1989a, pp. 158-9; 1989b n. 5). Tamsin must have evidence that her belief would be self-fulfilling. If she has evidence that she's been glued to her armchair, for example, or that her motivation for going to bed is very weak, she might not know that her decision to go to bed would be self-fulfilling. ${ }^{2}$ So she wouldn't be epistemically free. But if she knows the counterfactuals are true, she is licensed to believe in different ways.

If Velleman's account works, we have a neat explanation of how we usually know what we're doing as we begin to do it_-forming a decision simply is forming a justified belief about what we're going to do. And we seem to explain our freedom in practical deliberation in terms of something much more familiar - the kind of justification we have in theoretical reasoning. If Tamsin really is justified in forming various beliefs about what she's going to do, this might explain how she appears free. While Velleman's explanation relies on Tamsin having a desire to know what she's doing, perhaps such a desire isn't so strange. Our lives as agents wouldn't go well if we often didn't know what we were doing. And this desire need not be a conscious or person-level.

To summarise, Velleman's account has the following important features. It identifies decisions as beliefs. It takes forming these beliefs to be justified. And it uses this justification to explain apparent freedom. The special justification agents have in decision contexts means they aren't constrained by evidence of what they'll do. And this unconstraint looks to be just the thing to account for apparent freedom in

\footnotetext{
2 This has the result that actions that we're highly motivated towards can't be decided on, a result Velleman acknowledges (1989a, p. 159). While this is a serious concern for Velleman's account, I won't pursue it here.
} 
deliberation - it is a special kind of epistemic freedom agents only have while deliberating, and it explains apparent freedom without using metaphysical notions of freedom.

\subsection{Decisions as Unconstrained Self-constituting Beliefs}

Joyce and Ismael defend variants of Velleman's account (Joyce 2002, pp. 94-8; 2007 pp. 556-61; Ismael 2007, pp. 5-7; 2012, pp. 153-165). They agree with Velleman that decisions are beliefs, and that agents justifiably form these beliefs unconstrained by evidence. But rather than taking decisions to be beliefs in actions, they are beliefs in the very decisions themselves. The belief in the decision is the decision. Tamsin's deciding to go to bed, for example, is her forming the belief that she decides to go to bed. The belief does not cause the states of affairs it represents-it constitutes this state of affairs. ${ }^{3}$ The belief in the decision is self-constituting. While Joyce and Ismael call these beliefs 'self-fulfilling', I'll reserve that term for beliefs that are casually self-fulfilling.

Ismael and Joyce liken these self-constituting belief-formings to speech acts called performatives. When Ben asserts 'I hereby promise...', his act of asserting constitutes his promising. In asserting, Ben is unconstrained by prior evidence of whether he will make the promise, or what he will do (Ismael 2012, p. 155; 2007, p. 5; Joyce 2002, p. 97). Joyce and Ismael claim that because beliefs in decisions are self-constituting, we are similarly justified in forming them unconstrained by evidence. As Joyce puts it, 'The decision-maker is 'never "hemmed in" by her evidence' (2002, p. 98). Or in

\footnotetext{
${ }^{3}$ Does this identification lead to an infinite regress of beliefs in decision? While Joyce and Ismael don't discuss this, presumably the decision gets its content through its causal connections to action, and so a regress is avoided. These reflexive beliefs are still odd, but I won't take that as a reason to reject them.
} 
Ismael's words:

...evidence is irrelevant because I cannot be wrong. My beliefs about my own pending decisions [are] epistemically unconstrained by any information I might have...Any information I might already have is automatically overridden by the decision process itself, and (hence) it can't constrain its development. (2012, p. 154, her emphasis)

The agent can form whatever belief she likes, safe in the knowledge that it will turn out to be true. There are still some constraints. For a belief in a decision to be a decision, the belief must be formed during deliberation on how to act (Joyce 2002, p. 97; Ismael 2012, p. 154). And, at least explicitly for Joyce, the agent must believe that the decision will also cause the corresponding act (2002, p. 97). But within these constraints, agents can be justified in forming a variety of incompatible beliefs in their decisions - they have 'epistemic freedom' (Joyce 2002, p. 96), a connection Ismael also notes (2012, p. 156).

Joyce and Ismael's account seems to deliver the same important benefits as Velleman's - it gives an explanation of our apparent freedom in deliberation that does not invoke metaphysical abilities on the part of the agent. The account is also more economical, in that it does not appeal to a desire to explain why beliefs are selffulfilling (even though a mechanism will be needed to explain how these beliefs lead to action). Forming incompatible beliefs is justified because they constitute decisions. 


\subsection{Ignorance Conditions}

A rather different type of account relies instead on ignorance. Levi and Kapitan both offer accounts of decision-making that appeal to ignorance conditions. According to Kapitan $(1986,1989)$, an agent only believes she is free in deliberation if she takes herself to be ignorant of what option she will choose. Typically this will be explained by her actually being ignorant. According to Levi (1986, ch. 4; 1997, chs. 2 and 4; 2000, pp. 393-6), an agent can only recognise an option as available if it is a 'serious possibility' for her - a possibility not ruled out of consideration by her beliefs. An agent must be ignorant during deliberation of what option she will choose, for all but trivial forms of deciding. Under both these accounts, agents are not required to form beliefs unconstrained by evidence. Instead their evidence, in the form of their beliefs, leaves open how they will decide. In Levi's slogan deliberation 'crowds out' prediction $\left(1997\right.$, p. 32). ${ }^{4}$

Based on Levi's and Kapitan's conditions, I take the two central features of an ignorance account to be: a) agents must be ignorant of what they will decide and do if they are to appear free to deliberate; b) their ignorance partly explains their apparent freedom. Because facts about belief explain the appearance of freedom, this is an account of epistemic freedom. While neither Kapitan nor Levi gives an account of precisely this form, their conditions suggest such a possibility. Unlike unconstraint accounts, an ignorance account does not take decisions to be beliefs. Decisions merely imply beliefs about what one is going to do, and no reduction of decision to other states is given.

\footnotetext{
${ }^{4}$ Or perhaps, more accurately to my purposes, "prediction crowds out deliberation”. Similar conditions are explored in Shackle (1958), Ginet (1962), Harman (1976), Jeffrey (1977), Schick (1979), Gilboa (1999) and Spohn (2007).
} 
Ignorance conditions come in various strengths. Levi (1997, pp. 32, 76), for example, draws on Spohn (1977, pp. 114-5) to argue that agents can't properly have beliefs of any degree in their decisions while deliberating. If we measure degrees of belief by the usual means, offering bets, the bets offered can affect what decision an agent makes, and so can't be used to measure independent degrees of belief. But all this shows is that degrees of belief can't be measured by the usual means. For further argument, see Joyce (2002, pp. 86-7) and Rabinowicz (2002). Agents can still usefully and coherently assign probabilities to their decisions while deliberating, based on how committed they feel, or based on other evidence. Such predictions can help them make further plans, even while the outcomes of their deliberations are unsettled. This is why the ignorance account I advocate is more modest, requiring only that options are serious possibilities.

There are also accounts that argue that an agent cannot predict her decisions because any prediction she makes cannot incorporate its own effects on her deliberation (Bennett 2004, pp. 175-6). Some of these accounts use an agent's ignorance to account for apparent freedom (Lloyd 2012). But these don't posit ignorance conditions on deliberation, precisely because they take it there is no need to. They are not the kind of accounts I am concerned with. ${ }^{5}$

\footnotetext{
${ }^{5}$ Dummett (1964) also appeals to ignorance. But he is concerned with what agents take themselves to be able to know independently of their decision, not with their actual beliefs in general. He is not concerned with whether belief in decision can rule out deliberation, which, as we'll see, is what unconstraint accounts and ignorance accounts disagree on.
} 


\section{Similar yet Different}

Unconstraint and ignorance accounts share features in common. The three accounts just outlined all include an epistemic gap between an agent's evidence while deliberating and what she believes as a result of decision. An agent's evidence while deliberating does not compel her to make any particular decision, or to form any particular belief about what she will decide or do. It is for this reason that these accounts might seem equally suitable for explaining why agents appear free to decide on different options in deliberation.

Price, in particular, sees the above three accounts as different expressions of the same underlying idea (2012, p. 529-30). He thinks the accounts enforce the same kind of epistemic gap between our evidence and our contemplated actions and decisions, and uses this to explain why we shouldn't take our decisions to be evidence of the past. Here's how he puts it. He begins with Joyce's later account (2007), which characterises decisions as causally self-fulfilling beliefs. Immediately following he suggests 'An alternative way to put this thought, preferable in my view, is to say that there is an important sense in which, as she deliberates, an agent simply does not have knowledge, beliefs, or credences about the action in question' (2012, p. 529, my emphasis). This is an ignorance account—Price even quotes from Rabinowicz's (2002) summary of Levi. Finally, Price claims we get to both these views by considering the 'epistemic authority' that agents have with respect to their own actions - their ability to trump predictive knowledge, 'rendering it necessarily unjustified' (2012, p. 529). He takes the source of this epistemic authority to be given by Ismael's account of decisions as self-constituting beliefs. 
Price appeals to all three types of epistemic freedom — a causal account (Joyce 2007), a self-constituting account (Ismael 2007) and an ignorance account (Levi, via Rabinowicz 2002). What he seems to have in mind is the following. Under unconstraint accounts, even though an agent might seem to have evidence while deliberating about what she'll decide, she really shouldn't take this to be evidence. Why? Because she knows she is free to contravene it. Like Dummett's chief (1964), she is free to 'bilk' or 'trump' her evidence by deciding otherwise. Her epistemic authority over her current decision leads to ignorance elsewhere. Ignorance accounts, like Levi's, then turn out to have their source in unconstraint accounts, since it is unconstraint accounts that explain an agent's epistemic authority. ${ }^{6}$

But unconstraint and ignorance accounts are importantly distinct. While both include an epistemic gap, the source of this gap and what explains apparent freedom are very different. Under ignorance accounts, the agent does not have evidence of how she will decide - this is why there is an epistemic gap between her evidence and what she decides, and why she appears free. Under unconstraint accounts, she is epistemically unconstrained by her evidence, regardless of what evidence she has. This is the source of the epistemic gap, and what explains her apparent freedom. Unconstraint accounts hold that an agent's predictive evidence during deliberation is irrelevant to her freedom to decide. Tamsin can be reliably informed that she'll go to bed, believe she'll go to bed, and be rational to do so, and yet sensibly deliberate about whether to go to bed. Under an ignorance account, she cannot. Only under an ignorance account does prediction prevent deliberation.

\footnotetext{
${ }^{6}$ Some of Levi's arguments do suggest this line (1997, p. 76). But the authority Levi appeals to is not epistemic, or explained in terms of unconstraint. And as noted in regards to betting (section 2.3), Levi's arguments on this point are weak.
} 
Velleman and Joyce in fact use unconstraint accounts to argue against ignorance conditions of the type Levi posits (Velleman 1989a pp. 149-153, 166; 1989b, pp. 78-80; Joyce 2002, p. 94). They are right to do so. Unconstraint accounts do not lead to ignorance conditions. If an agent's apparent freedom is explained independently of the beliefs she has about what she will do, her apparent freedom gives her no reason to give up these beliefs. What explains her apparent freedom is knowing her beliefs would be true if formed. This knowledge is independent of what beliefs she has about what she will do. If having these beliefs in no way gets in the way of her apparent freedom, the fact that she is deliberating gives her no reason to forgo them.

Furthermore, adding in ignorance conditions on top of unconstraint accounts leads to troubling epistemic consequences. Unconstraint accounts begin with the idea that an agent's evidence of what she'll decide does not constrain her deliberation. Adding in ignorance conditions would mean that the very fact that she is deliberating changes the import of her evidence. Even if Tamsin has been reliably told that she will decide to go to bed, the fact that knows she would be justified in contravening this evidence means she should no longer treat it as evidence. She should not form, and should give up, any beliefs based on it. But what an agent would be justified in doing does not change the import of her evidence. The evidence of what she will do remains just as strong. It may already be troubling for unconstraint accounts that Tamsin is justified in contravening her evidence (a worry I'll come to). It's rather worse for this kind of hybrid view if her justification leads her to no longer form beliefs based on her evidence. Unconstraint accounts and ignorance conditions are a fraught combination. They are distinct and should not be combined. 


\section{Problems for Unconstraint}

I'll now argue that unconstraint accounts face two serious problems. Firstly, they imply an agent has epistemic freedom over beliefs formed on the basis of evidence. Secondly, they rely on a flawed notion of justification. They require agents to be justified in forming beliefs unconstrained by evidence. But agents aren't so justified. So such justification doesn't explain apparent freedom.

\subsection{Epistemic Freedom over Evidence-based Beliefs}

Unconstraint accounts identify decisions as self-fulfilling or self-constituting beliefs, and claim we appear free in deliberation because we are justified in forming a variety of such beliefs, unconstrained by evidence. But a concern immediately arises: beliefs formed on the basis of evidence can also be self-fulfilling or self-constituting. So we can have epistemic freedom even over ordinary evidence-based beliefs. Say Tamsin is deliberating over whether she will go to bed. Her partner tells her she will, and, trusting this prediction, she forms the belief that she will. Even though her belief is formed on the basis of evidence, her desire to do what she expects still gives her additional motivation to go to bed. Stipulate that if this additional motivation were not engaged, she would have stayed up. In this case, her belief based on evidence is selffulfilling. Tamsin may know this belief is self-fulfilling, insofar as she generally knows her decision-like beliefs are self-fulfilling. There may be a second belief (say a belief that she'll take a bath) that satisfies these same conditions. Under Velleman's account, because these incompatible beliefs are self-fulfilling and represent themselves as such, Tamsin has epistemic freedom over them, and experiences apparent freedom. Yet these beliefs are based on evidence. 
A corresponding objection applies to Joyce and Ismael's account. Say Tamsin is deliberating about whether to go to bed and her partner tells her that she will decide to go to bed. She therefore forms the belief that this is what she decides. As far as beliefs in decisions generally cause actions, this one will also cause her to act. And because it is a belief in decision formed during deliberation, that causes the act, it counts as her decision. We can again stipulate that if she hadn't heard the prediction, she would have decided to stay up. And again a second incompatible belief can satisfy these same conditions. So her beliefs formed on the basis of evidence make a difference to how she decides. She has the same epistemic freedom, even though her beliefs are formed on the basis of evidence. Under both types of unconstraint accounts, an agent has epistemic freedom over ordinary evidence-based beliefs. So epistemic freedom cannot account for the particular kind of apparent freedom we have over decisions.

To be clear, the concern is not that evidence-based beliefs count as decisions. The concern is that an agent has epistemic freedom over beliefs that are formed on the basis of evidence. Under Velleman's account, a belief would need to satisfy further conditions to be a decision, such as being formed on the basis of desire. But these further conditions don't concern the justification of these beliefs, and so aren't required to account for epistemic freedom. There is also serious concern over the wrong beliefs counting as decisions. An agent might, for example, form a belief about what she will do based on evidence of her desires. Under Velleman's account, provided she does this knowingly, the belief will count as a decision. Bratman discusses a similar concern with regard to known side effects- beliefs in side-effects may be self-fulfilling and formed on the basis of desires, and so count as decisions 
(1991, pp. 123-5). Whether or not such counterexamples are successful, they help set up a dilemma. Either some evidence-based beliefs count as decisions, or agents have epistemic freedom over beliefs that aren’t decisions. Either is a problem for unconstraint accounts. My main point here is that agents will have epistemic freedom over the wrong kind of beliefs, whether or not they count as decisions.

The source of this problem is not that unconstraint accounts identify decisions as beliefs. The problem is they appeal to justification to explain apparent freedom, a kind of justification that applies to evidence-based beliefs as much as to decision-beliefs. So it does not explain why we have apparent freedom only over decisions. This means that the problem cannot be avoided by dropping the identification and taking beliefs to be a mere component part of decision. The same problem over justification would apply. Ignorance accounts of apparent freedom avoid this problem. This is not because they don't identify decisions as beliefs, but because they don't appeal to justification in forming beliefs to explain apparent freedom.

Defenders of unconstraint accounts might respond by adding in further conditions on epistemic freedom. They might require beliefs to be formed in response to desires, for example, and not on the basis of evidence. Under Velleman's account, this would amount to stipulating that agents only have epistemic freedom over beliefs that are decisions. But such additions would take these accounts far from any ordinary notion of epistemic justification. Forming a belief on the basis of desire does not contribute to its justification. So we would lose whatever insight epistemic justification was supposed to provide into apparent freedom. 
One could also respond by adding in ignorance conditions on deliberation. This is another way in which ignorance accounts avoid the problem. If agents cannot have or acquire evidence of their decisions or actions while deliberating, they will not form beliefs based on such evidence. But unconstraint accounts aim to avoid ignorance conditions. They take an agent to be justified in forming beliefs unconstrained by evidence. If agents could not deliberate when they had too much evidence, their justification in forming beliefs unconstrained by evidence would not explain their apparent freedom. ${ }^{7}$

I suspect defenders of unconstraint accounts would instead respond by claiming that an agent's epistemic freedom comes from her justification to ignore her evidence. It doesn't matter whether she actually ignores her evidence or not. But it does matter. An agent who knows she systematically only forms beliefs based on evidence, and has psychological mechanisms in place that guarantee this, should not be credited with the same epistemic freedom that we have.

\subsection{Forming Beliefs without Justification}

There is a second even more serious concern. Unconstraint accounts of epistemic freedom require that agents justifiably form beliefs unconstrained by evidence. This justification is meant to explain apparent freedom. But agents aren't justified in forming beliefs unconstrained by evidence. So we can’t appeal to this justification to explain apparent freedom.

\footnotetext{
${ }^{7}$ One could adopt a hybrid view that begins with ignorance conditions and adds in unconstraint, taking both to explain an agent's apparent freedom. This is similar to an ignorance account that also identifies decisions as beliefs. As far as I know, such accounts have never been explicitly advocated-Pears (1968) and Hampshire and Hart (1958, p. 3) perhaps come closest. But while a hybrid view avoids this first problem facing unconstraint accounts, it doesn't avoid a second.
} 
Here's how the explanation is supposed to go. Velleman, Joyce and Ismael claim that self-fulfilling and self-constituting beliefs are justified once formed. Once Tamsin has formed the belief that she'll go to bed, she has evidence of its truth, because she knows the belief is either self-fulfilling or self-constituting. This justification is meant to give her 'license' to form such beliefs now (Velleman 1989b, p. 74, passim), imply she is not 'hemmed in' by her evidence (Joyce 2002, p. 98) and make her evidence of what she will do 'irrelevant' (Ismael 2012, p. 154). But these further steps are far from trivial. As Grice (1971, p. 267-8), Langton (2004) and Setiya (2008, pp. 400-1) all argue, agents are not justified in forming beliefs in the absence of adequate grounds, even if they know the beliefs will be justified and true once formed. Nor are agents justified in ignoring their evidence. These points have been persuasively argued before, so I will be brief. Justification to form beliefs depends on what grounds or evidence agents have - not on what evidence they would have, were they to believe differently and have different evidence. Before Tamsin decides, she doesn't have evidence that she'll go to bed and evidence that she'll stay up. It is not the case that, for each belief, she is justified in forming it. At most she has evidence of one of these. She may be justified in either belief once she forms it. But that is a different matter.

Consider the following case, a variant of one discussed by Langton (2004, pp. 257-8). Tamsin's son Carlo is thinking about what Santa will get him for Christmas. He has inductive evidence from previous years that any belief about what he'll get (within reason) will be justified if formed — when he forms the belief that he'll get toy bear, he gets it, and so on for other gifts. Moreover, these beliefs are self-fulfilling-if he didn't form the belief that he'll get a toy bear, his mother wouldn't know to buy him 
one, and he wouldn't get one. Carlo is licensed, in Velleman's sense, to form various incompatible beliefs about what he will get. These beliefs are self-fulfilling and Carlo has evidence they will be justified once formed. And yet it seems Carlo is not justified in forming these beliefs. His evidence does not license him to. He may wishfully form these beliefs, but not justifiably. Nor should we ascribe the fault to Carlo's mistaken beliefs about Santa. Enlightened-Carlo, who has realised the role his mother plays in making his beliefs self-fulfilling, still isn't justified in forming them.

Langton (2004) and Setiya (2008) describe similar cases as involving 'faith' or 'wishful thinking', where agents go beyond their evidence in forming beliefs. But it's rather worse. Agents are not only licensed to go beyond their evidence, but to contradict and go against their evidence. Even if an agent has complete evidence that entirely settles what he will decide and do, unconstraint accounts require him to be justified in believing otherwise. Even if 'the agent is confronted by all of the evidence about his future action, and...fully appreciates its evidentiary force...[t] evidence cannot require the agent to draw a particular conclusion about what he'll do' (Velleman 1989a, p. 153). This is why I have insisted on calling these accounts unconstraint accounts: evidence of what an agent will do in no way constrains him.

Nor is it only external or partial evidence that agents are unconstrained by. Unconstraint takes a very strong form - agents are unconstrained by even complete knowledge of their own motivations. Velleman, in particular, is explicit that evidence of motives that 'constitutes compelling evidence for expecting [an agent] to perform one action rather than another... still cannot compel the agent himself' (1989, p. 150). 
Given how strong unconstraint needs to be, we have even less reason for thinking forming unconstrained beliefs is justified.

If agents aren't justified in forming these belief-like states, we have even less reason to identify them as beliefs. We expect beliefs to be formed in response to epistemic grounds. We may also question the psychological possibility of forming such beliefs. But more importantly, if agents are not justified in forming these beliefs, we have no account of how agents appear free to form them. This is what the justification was supposed to provide. So unconstraint accounts do not explain how agents appear free. Ignorance accounts avoid this problem, precisely because they don't appeal to this justification to explain apparent freedom.

\section{The Underlying Trouble}

Unconstraint accounts imply we experience apparent freedom even over evidencebased beliefs, and they rely on a faulty notion of justification. In this final section, I argue for a diagnosis of what has gone wrong - unconstraint accounts implicitly presuppose an unexplained apparent ability to form beliefs at will. Only given this apparent freedom do unconstraint accounts look promising. But this is a kind of freedom that makes epistemic freedom redundant.

I've argued that unconstraint accounts don't explain apparent freedom, because agents aren't justified in forming the relevant beliefs. But one might think that an agent's apparent freedom is actually explained by the justification an agent would have, were she to form the belief. Perhaps this is the relevant justification, and so the second problem is avoided. However, to appeal to this conditional justification, we'd need to 
identify a sense in which the agent takes it she could or might form such beliefsminimally, a modality in which such beliefs appear possible. Only with this additional modality might the justification she has once these beliefs are formed explain her apparent freedom now.

To see why an additional modality is required, consider examples of agents who know a belief would be self-fulfilling, were they to form it, but who correctly takes it they will not and cannot form the belief. Unconstraint accounts might introduce further conditions to rule out such cases. My point here is simply that some further notion of possibility is being presupposed. First, consider Raamy, who knows that if he were to believe he will swim into a river (teeming with crocodiles), he will indeed swim into this river, given how stubborn he is about acting as he believes. He is Velleman's agent par excellence, who is strongly motivated to act as he expects, and does not fall prey to weakness of will. But Raamy also knows he is unable to form such a belief. He has such a fear of crocodiles that he can't even imagine swimming into the river, let alone believe he will. The mere thought of crocodiles fills him with such dread, that he is unable to conceive of himself in relation to them-any attempt to conceptualise, visualise or form a belief about swimming into the river fails. Raamy knows this about himself. And so he won't appear free to decide to swim into the river. He won't deliberate concerning this option and won't experience a feeling of freedom. But according to unconstraint accounts, as explicated so far, he will.

Or consider Yun, who knows she is unable to form the belief that she will compute the eigenvalues for a simple matrix in front of her. This is because she lacks the concept EIGENVALUE. She knows this about herself. When her teacher asks her to 
calculate the eigenvalues, she doesn't know what she is being asked. And when she is prompted with further clarification, in case she simply lacks the word 'eigenvalue', things go no better. She doesn't know what an eigenvalue is. But she is familiar with matrices and adept at basic arithmetic. If she were to form the belief that she will compute the eigenvalues of the matrix, this would imply her having the concept EIGENVALUE. Then she would indeed be able to compute the eigenvalues, and being a diligent student, would do so. So under unconstraint accounts, she has epistemic freedom. But like Raamy, in her present state, she would not appear free to decide to compute the eigenvalues. Similarly for the agent above (section 4.1) who knows she can only forms beliefs based on evidence. She would not appear free to decide in different ways. To rule out such cases, an additional modality is required in which agents are free to form beliefs. And perhaps with this new modality, agents won't turn out to have freedom over evidence-based beliefs (avoiding the first problem).

What sort of modality could defenders of unconstraint accounts appeal to? Could they appeal to an apparent 'metaphysical' freedom to make decisions in ways not causally or nomologically determined by prior states of affairs? Not likely. This would make apparent freedom mysterious, and take away whatever advantage came from appealing to ordinary beliefs. They could try an epistemic modality-the fact that various beliefs are compatible (or thought to be compatible) with the agent's other beliefs. But such an approach places ignorance conditions on deliberation. We wouldn't explain how agents appear free to form beliefs unconstrained by evidence. Ignorance would instead explain how agents appear free. 
Sometimes Velleman seems to appeal to the fact that certain beliefs are 'wishful' and responsive to desires, to explain why they appear suitably under an agent's control (1989a, pp. 69, 127). Sometimes he also appeals to the fact that agents don't form them in response to evidence (1989a, p. 25). And sometimes these ideas are combined: 'we believe what we believe because we want to, not because the evidence would have dictated it' (1989a, p. 162). But these appeals won't explain why agents appear free to form different beliefs. Regarding evidence, precisely what is in question is how an agent takes it she can form beliefs that are not in keeping with her evidence. We can't use an apparent ability to do so to account for this possibility. On the desire side, things fare no better. As Velleman is clear, an agent needs to appear free to form beliefs that are not in keeping with her greatest desires, or what she takes them to be $(1989$ a, pp. 145,150$){ }^{8}$ So her apparent freedom to form different incompatible beliefs cannot be explained by desire-responsiveness.

We could try appealing to a real or apparent primitive agent-ability. Sometimes Velleman claims that self-fulfilling beliefs are formed 'spontaneously' (1989a, p. 24), 'voluntarily' (1989a, p. 66) or 'at will' (1989a, p. 66 n. 27). But appealing to such primitives is not a promising approach. Beliefs are typically thought of as involuntary states that we simply find ourselves in. Precisely because beliefs are responsive to evidence and other epistemic grounds, they are not states we form at will. While it may turn out that we do have such an ability we can't appeal to a prior notion of it to explain apparent freedom. The more reasonable way of interpreting Velleman's account is that the appearance of forming beliefs at will is to be explained by his account of epistemic freedom. For support, see Roessler (2013, p. 43). But as we have

\footnotetext{
${ }^{8}$ Velleman might drop this requirement. But if desire-responsiveness is enough to explain apparent freedom, then, as I argue below, no detour via epistemic freedom is required.
} 
seen, there are no good candidates for explaining how we appear free to form different beliefs. Velleman's account of epistemic freedom presupposes a kind of modality we haven't yet explained.

Joyce runs into similar difficulties with this aspect of Velleman's account. He is explicit that forming beliefs is not a case of choice: 'one chooses acts, not choices' (2002, p. 95). But beyond characterising the process as an agent's 'making up her mind' (2002, p. 97), Joyce says nothing about what this apparent ability consists in. Ismael speaks of the 'decision process' as something 'I implement', and which overrides previous evidence (2012, pp. 154-5). And she sometimes speaks of the 'representational acts' and 'activity' of the deliberator (2007, p. 5). But these remarks give us no insight into how an agent implements deliberation or why forming beliefs appears as an activity at all—and so why an agent might appear free to form different beliefs. And if we think of deliberation as merely a changing stock of evidence, we still haven't identified how such changes are seen as possible.

What I suspect Velleman, Joyce and Ismael are relying on is a primitive apparent ability to form different beliefs, unconstrained by evidence — a kind of apparent psychological ability. If agents seem able to form beliefs unconstrained by evidence, and yet still end up with justified beliefs, this might seem to account for apparent freedom in deliberation. I don't think agents have such an apparent ability, given the arguments above — we form beliefs involuntarily in response to our epistemic grounds. But even if we grant this primitive apparent ability, the epistemic justification of such beliefs no longer plays a role in explaining apparent freedom. Epistemic freedom becomes redundant. Once agents have a primitive apparent ability 
to form different beliefs we have simply granted them a primitive apparent ability to make different decisions. No further explanation is required for apparent freedom in deliberation. The justification an agent may have in forming these beliefs plays no role in explaining how she sees herself as free with respect to them. Justification may still play a role in explaining why these states count as beliefs, but not in explaining apparent freedom. For this purpose, we have no reason to adopt an unconstraint account over an account that simply gives agents a primitive apparent ability to decide.

This result has important consequences for how unconstraint accounts of epistemic freedom are used. Joyce (2002) uses epistemic freedom to argue that agents can be certain of how they will decide, and yet have available options. But if epistemic freedom doesn't offer an account of apparent freedom, it turns out Joyce is simply presupposing that agents have a primitive apparent freedom to decide unconstrained by evidence. We have no support for such a view.

A similar point holds for accounts that appeal to 'bilking'. The idea is that any evidential correlation between a known state of affairs and a decision can be bilked by the agent deciding in some other way (Dummett 1964; Price 2012, p. 529; Ismael 2012, p. 161). For example, if Tamsin knows it is 11 o'clock and is told that she reliably decides to go to bed when it's 11 o'clock, she can bilk this correlation by deciding to stay up. So there can't be secure correlations between decisions and known states of affairs. Appeals to bilking don't explain freedom in terms of beliefs, and so don't count as accounts of epistemic freedom. But they rely on a primitive notion of the same kind as unconstraint accounts. And like unconstraint accounts, 
they don't actually explain freedom to decide, and so provide no support for the idea that all known evidential relations can be bilked. Bilking accounts, like unconstraint accounts, give no guidelines for when deliberation is possible and when bilking can occur. So they have limited application when used in accounts of causation-a topic I save for another time.

\section{Conclusion}

Unconstraint accounts of epistemic freedom fail to account for apparent freedom in deliberation. They imply we have epistemic freedom even over evidence-based beliefs. And they rely on a flawed notion of justification - they require agents to be justified in forming beliefs unconstrained by evidence. Unconstraint accounts look promising only insofar as they presuppose a primitive apparent ability to believe at will. But this is an ability that makes epistemic freedom redundant. A strong alternative account appeals instead to epistemic possibility and ignorance to explain apparent freedom. Ignorance accounts don't rely on an agent's justification, avoiding the problems above. But to see this promising alternative, ignorance and unconstraint accounts must be carefully distinguished.

\section{References}

Bennett, Jonathan. 2004. Time in Human Experience. Philosophy 0(2): 165-183.

Bratman, Michael. 1991. Cognitivism about Practical Reason. Ethics 102(1), $117-128$.

Dummett, Michael. 1964. Bringing about the Past. The Philosophical Review 73 (3): 338-359.

Gilboa, I. 1999. Can Free Choice be Known. In C. Bicchieri, R. Jeffrey and B. Skyrms (eds.) The Logic of Strategy. Oxford: Oxford Uni. Press. 
Ginet, Carl. 1962. Can The Will be Caused? The Philosophical Review 71(1): 49-55.

Grice, H. P. 1971. Intention and Uncertainty. Proceedings of the British Academy 57: 263-79.

Harman, Gilbert. 1976. Practical Reasoning. The Review of Metaphysics 29(3): $431-463$.

Hampshire, Stuart \& Hart, H. L. A. 1958. Decision, Intention and Certainty. Mind 67(265): 1-12.

Hitchcock, Christopher. 1996. Causal Decision Theory and Decision-theoretic Causality. Noûs 30: 508-26.

Ismael, Jenann. 2007. Freedom, Compulsion and Causation. Psyche 13(1): 1-11.

- 2012. Decision and the Open Future. In A. Bardon (ed.) The Future of the Philosophy of Time. London: Routledge.

Jeffrey, Richard C. 1977. A Note on the Kinematics of Preference. Erkenntnis 11(1): 135-141.

Joyce, James M. 2002. Levi on Causal Decision Theory and the Possibility of Predicting One's Own Actions. Philosophical Studies 110(1), 69-102.

—. 2007. Are Newcomb Problems Really Decisions? Synthese 156: 537-62.

Kapitan, Tomis. 1986. Deliberation and the Presumption of Open Alternatives. The Philosophical Quarterly 36(143): 230-251.

1989. Doxastic Freedom: A Compatibilist Alternative. American

Philosophical Quarterly 26: 31-41.

Langton, Rae. 2004. Intention As Faith. Royal Institute of Philosophy Supplement 55 Supplement: 243-258.

Levi, Isaac. 1986. Hard choices. Cambridge: Cambridge Uni. Press. 1997. The Covenant of Reason. Cambridge: Cambridge Uni. Press.

- 2000. Review of James M. Joyce: The Foundations of Causal Decision Theory. Journal of Philosophy 97(7), 387-402.

Lloyd, Seth. 2012. A Turing Test for Free Will. Philosophical Transactions of the Royal Society A 370: 3597-3610.

Mellor, D. Hugh. 1988. On Raising the Chances of Effects. In James H. Fetzer (ed.) Probability and Causality. Dordrecht: Reidel. 229-39. 
Pears, David. 1968. Predicting and Deciding. In P. F Strawson (ed.) Studies in the Philosophy of Thought and Action. Oxford: Oxford Uni. Press.

Pearl, Judea. 2000. Causality: Models, Reasoning and Inference. Cambridge: Cambridge Uni. Press.

Price, Huw. 1992. Agency and Causal Asymmetry. Mind 101: 501-520.

- 2012. Causation, Chance, and the Rational Significance of Supernatural Evidence. Philosophical Review 121(4): 483-538.

Rabinowicz, Wlodek. 2002. Does Practical Deliberation Crowd Out Self-Prediction? Erkenntnis 57(1): 91-122.

Roessler, Johannes. 2013. The Epistemic Role of Intentions. Proceedings of the Aristotelian Society 113: 39-56.

Schick, Frederic. 1979. Self-knowledge, Uncertainty, and Choice. British Journal for the Philosophy of Science 30: 235-252.

Shackle, G. L. S. 1958. Time in Economics. Amsterdam: North Holland Pub. Co.

Setiya, Kieran. 2008. Practical Knowledge. Ethics 118: 388-409.

Spohn, Wolfgang. 1977. Where Luce and Krantz do Really Generalize Savage's Decision Model. Erkenntnis 11: 113-134.

- 2007. The Core of Free Will. In P. K Machamer \& G. Wolters (eds.) Thinking about Causes. Pittsburgh: Pittsburgh Uni. Press. 2007

Velleman, J. David. 1985. Practical Reflection. The Philosophical Review 94(1) 33-61.

—. 1989a. Practical Reflection. Princeton: Princeton University Press.

—. 1989b. Epistemic Freedom. Pacific Philosophical Quarterly 70: 73-97.

- 2000. The Possibility of Practical Reason. Oxford: Oxford Uni. Press. 